\title{
Changes in Physicochemical Characteristics and Antioxidant Activity of Acorn (Quercus acutissima) under Different Heat Treatment Conditions
}

\author{
Soojin Park, SungHoon Jung \\ Oriental Medical Food \& Nutrition Major, Semyung University Graduate School \\ sjpark@semyung.ac.kr
}

\begin{abstract}
The present study was undertaken to analyze the changes in the physicochemical characteristics and antioxidant activity in acorn (Quercus acutissima) under various temperature treatments: $A\left(140^{\circ} \mathrm{C}\right), B\left(150^{\circ} \mathrm{C}\right), \mathrm{C}\left(160^{\circ} \mathrm{C}\right), \mathrm{D}\left(170^{\circ} \mathrm{C}\right)$, and $\mathrm{E}\left(180^{\circ} \mathrm{C}\right)$. Each treatment sample was extracted with hot water for $4 \mathrm{~h}$ at $60^{\circ} \mathrm{C}$. The $\mathrm{pH}$ of all heat-treated acorn extracts was significantly lower than that of the control, unheated acorn extract, and the $\mathrm{pH}$ was inversely proportional to the treatment temperature $(p<0.05)$. The sugar content of the acorn extract was significantly higher after heat treatment than that of the control $(p<0.05)$; however, it was higher than the control only in the groups below $160^{\circ} \mathrm{C}$. Total polyphenol content was the highest in the group treated to the lowest temperature $\left(A: 140^{\circ} \mathrm{C}\right)$, at $31.59 \pm$ $0.21 \mathrm{mg} \mathrm{GAE} / \mathrm{g}(\mathrm{p}<0.05)$. Antioxidant activity was influenced in a dose dependent manner $(p$ $<0.05)$ being 31.03-95.99\% for DPPH radical scavenging activity and $20.49-99.51 \%$ for ABTS radical scavenging activity in doses of $0.12-1.00 \mathrm{mg} / \mathrm{mL}$ of heat treated acorn extract. In conclusion, heat treatment of acorn fruits increased sugar content and antioxidant content as well as activity of acorn extracts, especially under lower heat treatment conditions.
\end{abstract}

Keywords: acorn, heat treatment, polyphenol, antioxidant

\section{Introduction}

The term 'Acorn' (Quercus spp.) encompass all fruits in the family Fagaceae, which are found worldwide [1]. In South Korea, the acorn mainly refers to the fruit of Q. acutissima [2]. Since acorns are non-toxic and contain approximately 65-70\% starch [3], they have traditionally been used as a food resource during times of shortages in spring. To completely remove the tannins that create the characteristic astringent taste of acorns, the fruits are treated with water, from which starch powder is produced to make foods such as muk or jeonbyeong [4]. Moreover, in Donguibogam (東醫寶鑑) and Ben Cao Gang Mu (本草綱目), it is stated that acorns are effective in treating gastroenteritis, fatigue recovery, and relief from hangovers [4]. Recent studies report that acorns are rich in gallic acid, digallic acid, and gallotannin ${ }^{1}$ components, as well as in tannic acid, all of which are known to be excellent antioxidants. These all have antioxidant, anticancer, and antiviral activities; are effective in eliminating radioactive materials; and may be effective as anti-dementia drugs [5]. Heat treatment of foods induces reactions such as degradation, synthesis, and condensation in raw material components, leading to elevation in solid contents, and alterations in the activities of various bioactive substances [6]. During heat treatment, a non-enzymatic browning reaction (Maillard reaction)

Article history:

Received (September 4, 2017), Review Result (October 16, 2017), Accepted (December 3, 2017) 
occurs, which creates a brown, melanoidin pigment from interaction between carbonyl compounds of sugars and nitrogenous compounds of the amino group via various intermediate steps. During this reaction, various flavor components are generated in the food, which undergo color change, and subsequently, there is induction of antioxidants that have strong antioxidative effects on lipid acidification [7]. To date, studies have been mainly focused on producing foods such as muk, tteok, dasik, cookies, and muffins using acorn starch; improvements in serum lipid content that depend on the addition of acorn starch; and antidiabetic and anti-obesic efficacies of acorn powder. Recently, it was proposed to use acorn as tea by heat treatment such as frying or steaming [8]. However, fundamental data about changes in the characteristics of acorn that might be dependent on temperature during heat treatment are lacking. Therefore, the present study aimed to provide fundamental data to identify characteristics of acorn under different heat treatments. To achieve this, acorn heated to different temperatures and changes in their physicochemical components and antioxidants and their activities were compared.

\section{Materials and Methods}

\subsection{Materials}

Acorn used in the present study were purchased with their coats removed from a traditional market in Chungbuk province in 2015. An expert performed heat treatments using a roaster (Duett-M, Probat, Emmerich, Germany) under various temperature conditions: A $\left(140^{\circ} \mathrm{C}\right), \mathrm{B}$ $\left(150^{\circ} \mathrm{C}\right), \mathrm{C}\left(160^{\circ} \mathrm{C}\right), \mathrm{D}\left(170^{\circ} \mathrm{C}\right)$, and $\mathrm{E}\left(180^{\circ} \mathrm{C}\right)$ for $4 \mathrm{~min}$, the samples were stored in the freezer until analysis. All acorn samples were ground using a food grinder (KSP-35, Koreamei Co. Ltd. Korea) for $30 \mathrm{~s}$, homogenized with a 50 -mesh, and extracted with $20 \times$ hot water $\left(60^{\circ} \mathrm{C}, 4 \mathrm{~h}\right)$, followed by centrifugation $\left(4,000 \mathrm{rpm}, 4^{\circ} \mathrm{C}, 15 \mathrm{~min}\right)$. The supernatant was then collected and stored in a freezer until analysis.

\subsection{Methods}

Measurement of $\mathrm{pH}$ and sugar contents: Acorn extracts from heat treatments in a series of temperatures were diluted 50-fold and then $\mathrm{pH}$ and sugar content were measured three times using a pH meter (Orion 3 Star, Thermo, Singapore) and saccharometer (PR-201, Atago, Co. Ltd. Japan), respectively.

Total polyphenol measurement: The content of total polyphenol compounds was measured based on the method described by Folin and Denis [9]. One milliliter of extract after adjustment of concentration $(1 \mathrm{mg} / \mathrm{mL})$ was mixed with $2 \mathrm{~mL}$ of $2 \%$ sodium carbonate, and incubated at room temperature for $3 \mathrm{~min}$, to which $1 \mathrm{~mL}$ of $1 \mathrm{~N}$ Folin-Ciocalteu phenol reagent was next added and the mixture was incubated in the dark for $30 \mathrm{~min}$, followed by measurement of optical density (Optizen 3220UV, Mecasys, Daejeon, Korea) at $750 \mathrm{~nm}$. After creating a standard curve using gallic acid as the reference, the total polyphenol content of each sample was calculated.

Antioxidant activity measurement: The 2,2- diphenyl-1-picrylhydrazy (DPPH) radical scavenging activity was measured by the Blois method [10] with partial modification. Acorn extracts after heat treatment at various temperatures were prepared at different concentrations $(0.12,0.25,0.50$, and $1.00 \mathrm{mg} / \mathrm{mL})$, and $4 \mathrm{~mL}$ of $0.1 \mathrm{mM} \mathrm{DPPH}$ was added to $1 \mathrm{~mL}$ of each extract, followed by incubation in the dark for $30 \mathrm{~min}$, after which the sample was mixed for $30 \mathrm{~s}$ and the optical density (Optizen 3220UV, Mecasys, Daejeon, Korea) was measured at 517 $\mathrm{nm}$. 
The 2, 2'-azino-bis (3-ethylbenzothiazoline-6-sulfonic acid) (ABTS) radical scavenging activity was measured by the Re method [11] with partial modification. A $900 \mu \mathrm{L}$ sample of diluted ABTS solution was mixed with $100 \mu \mathrm{L}$ of roasted acorn extract prepared in different concentrations $(0.12,0.25,0.50$, and $1.00 \mathrm{mg} / \mathrm{mL})$ and reacted in the dark for $10 \mathrm{~min}$, followed by measurement of optical density (Optizen 3220UV, Mecasys, Daejeon, Korea) at $734 \mathrm{~nm}$. The equations for DPPH and ABTS scavenging activities were presented as optical density ratio $(\%)$ between groups with sample solution and groups without solution, with distilled water used as a negative control.

Statistical analysis: All measurements were repeated three times and the SPSS software program (version 18.0, package for Social Science, SPSS Inc. Chicago, IL USA) was used for statistical analysis. To test statistical significance, analysis of variance was performed and, in case of significance, Duncan's multiple range test was applied at $\mathrm{p}<0.05$ as a post-hoc test.

\section{Results}

\section{1 pH and sugar content of acorn extracts subjected to heat treatments under different temperatures}

The $\mathrm{pH}$ of acorn extracts under different heat treatment temperatures ranged from 5.43 to 6.18 , and the value significantly decreased as temperature increased $(\mathrm{p}<0.05)$. Sugar content was $0.50-1.11^{\circ} \mathrm{Bx}$ and increased in the $\mathrm{A}-\mathrm{C}$ groups and then decreased at higher temperatures Table 1.

\section{Table 1 Physicochemical characteristics of acorn extract according to heat treatment temperatures}

\begin{tabular}{ccc}
\hline Sample & $\mathrm{pH}$ & Sugar content $\left({ }^{\circ} \mathrm{Bx}\right)$ \\
\hline control & $6.18 \pm 0.02^{\mathrm{a}}$ & $0.50 \pm 0.01^{\mathrm{d}}$ \\
A & $5.70 \pm 0.01^{\mathrm{b}}$ & $1.11 \pm 0.01^{\mathrm{a}}$ \\
B & $5.70 \pm 0.02^{\mathrm{b}}$ & $1.00 \pm 0.02^{\mathrm{b}}$ \\
C & $5.63 \pm 0.03^{\mathrm{c}}$ & $1.10 \pm 0.02^{\mathrm{a}}$ \\
D & $5.56 \pm 0.01^{\mathrm{d}}$ & $0.90 \pm 0.03^{\mathrm{c}}$ \\
E & $5.43 \pm 0.03^{\mathrm{e}}$ & $0.93 \pm 0.06^{\mathrm{c}}$ \\
\hline
\end{tabular}

Values with different letters in superscripts within a column are significantly different at $\mathrm{P}<0.05$ by Duncan's multiple range test.

\subsection{Total polyphenol content of acorn extracts subjected to heat treatments under different temperatures}

Total polyphenol content of acorn extracts under different temperatures were significantly higher after heat treatment than in the control $(19.33 \pm 0.18 \mathrm{mg}$ gallic acid equivalent [GAE]/g). The A group that had the lowest temperature $\left(140^{\circ} \mathrm{C}\right)$ contained the highest total polyphenol content $(31.59 \pm 0.21 \mathrm{mg} \mathrm{GAE} / \mathrm{g})$, which was $163 \%$ greater than that in the control. However, total phenol content of acorn extract significantly decreased as temperature in the heat treatment groups increased $(\mathrm{p}<0.05)$ Figure 1. 


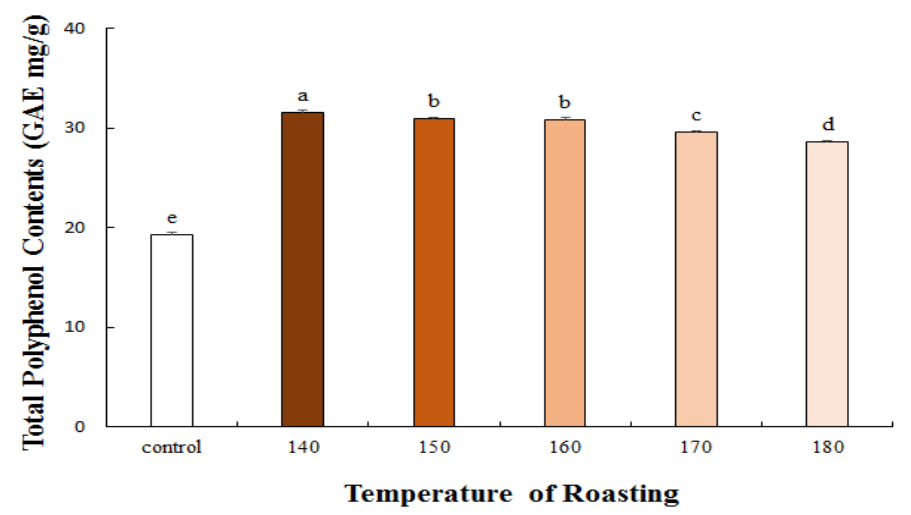

Figure 1 Total polyphenol content of acorn extracts subjected to heat treatment under different temperatures

\subsection{Antioxidant activities of acorn extracts subjected to heat treatments under different temperatures}

DPPH and ABTS radical scavenging activities of acorn extracts significantly increased as the concentration increased Figures 2 and 3. Heat treatment also significantly increased the antioxidant activities of acorn extracts compared with that in the control. Heat treatments increased DPPH and ABTS radical scavenging activities by $31.03-95.99 \%$ and $20.49-99.51 \%$, respectively. When comparing the temperature in the heat treatments, A group with the lowest heat treatment temperature $\left(140^{\circ} \mathrm{C}\right)$ had the highest antioxidant activity $(\mathrm{p}<0.05)$. Difference in antioxidant activity was particularly prominent at lower concentrations. DPPH activity significantly decreased in D group $\left(170^{\circ} \mathrm{C}\right)$ and $\mathrm{E}$ group $\left(180^{\circ} \mathrm{C}\right)(\mathrm{p}<0.05)$, whereas, at lower temperatures, ABTS radical scavenging activity also decreased with increasing heat treatment temperature $(\mathrm{p}<0.05)$.

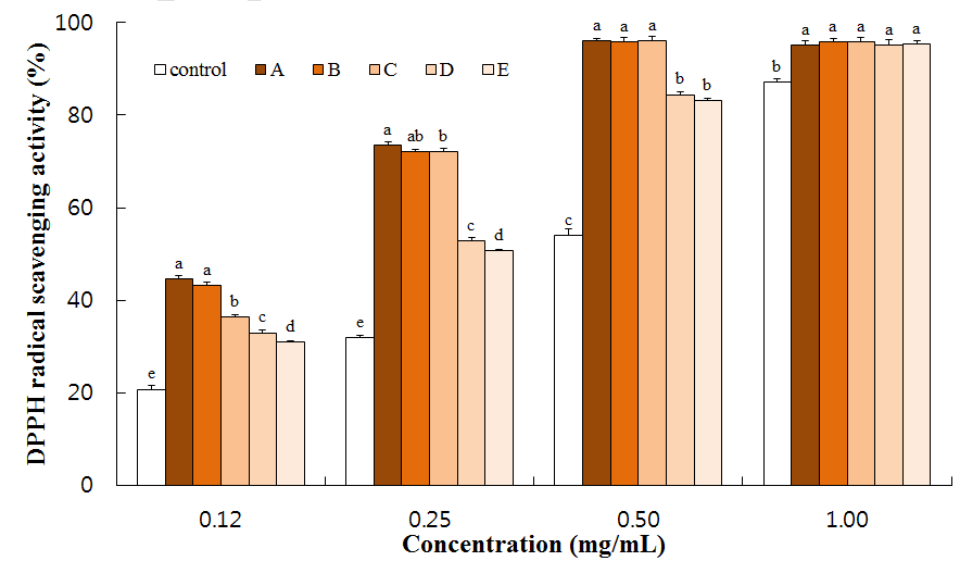

Figure 2 DPPH radical scavenging activities of acorn extracts varying by temperature in heat treatment 


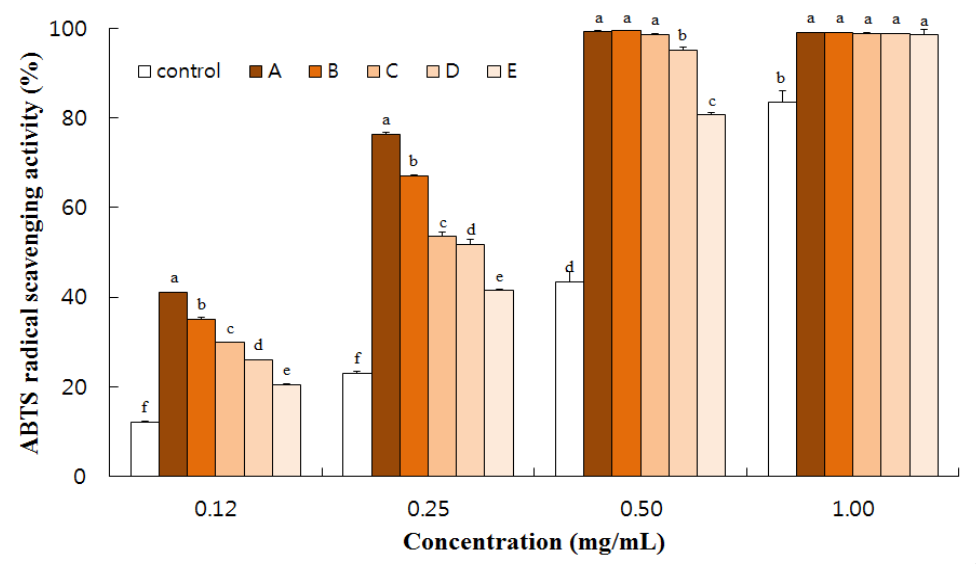

\section{Figure 3 ABTS radical scavenging activities of acorn extracts varying by temperature in heat treatment}

\section{Conclusion}

The present study investigated the changes in physicochemical characteristics, and antioxidants and their activities in acorn extracts after heat treatment under various temperature conditions. When acorns were subjected to heat treatment under various temperature conditions, from $140^{\circ} \mathrm{C}$ to $180^{\circ} \mathrm{C}$, the $\mathrm{pH}$ of acorn extracts decreased depending on heat treatment temperature, whereas their sugar content was increased. In addition, total polyphenol contents and antioxidant activities decreased with heat treatment, in which the group with the lowest treatment temperature $\left(140^{\circ} \mathrm{C}\right)$ had the highest polyphenol content and antioxidant activity. The present study investigated the effect of different temperatures on the various physiologically active components of acorn, based on the findings of which, it is expected that the use of acorn as a potential macrobiotic, other than a starch source, will be emphasized on.

\section{ACKNOWLEDGEMENTS}

This study was conducted with support from the Academic Research Grant of Semyung University in 2016.

\section{References}

[1] G. J. Yook, H. J. Lee and M. K. Kim, Korean J. Nutr. 35, 171-182 (2002)

[2] S. H. Kim and J. M. Lee, Korean J. Food Preserv. 15(1), 58-65 (2008)

[3] T. H. Shim, Y. S. Jin, J. H. Sa, I. C. Shin, S. I. Heo, and M. H. Wang, Korean J. Food Sci. Technol. 36(5), 800-803 (2004)

[4] T. W. Kim, MS-Thesis Seoul-City National University, Korea, 32-41 (2002)

[5] S. H. Lee, D. I. Kim, S. Y. Cho, H. J. Jung, S. M. Cho, H. J. Park, and H. S. Liiehoj, J. Korean Soc. Food Sci. Nutr. 34(5), 738-742 (2005)

[6] R. J. Redgwell, V. Trovato, and D. Curti, Food Chem. 80 (4), 511-516 (2003)

[7] C. S. Suh, and J. K. Chun, Korean J. Food Sci. Technol. 13(4) 334-339 (1981)

[8] H. K. Kim, PhD-Thesis, Daegu Haany University, Korea, 1-4 (2016)

[9] O. Folin, W. Denis, J. Biol. Chem. 12, 239-243 (1912)

[10] M. S. Blois, Nature. 181, 1199-1200 (1958) 
[11] R. Re, N. Pellegrini, A. Proteggente, A. Pannala, M. Yang, and C. Rice-Evans, Free Radic. Biol. Med. 26(910), 1231-123 (1999)

\section{Authors}

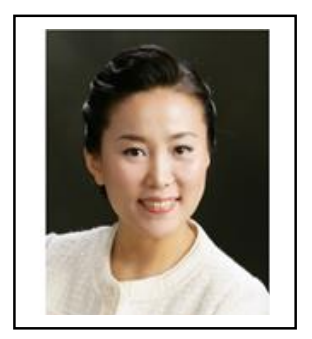

\section{Dr. Soojin Park}

Associate professor,

Oriental Medical Food \& Nutrition Major,

Semyung Univ. Graduate School and School of Food \& Nutritional Science of Bio-industry, Semyung Univ.

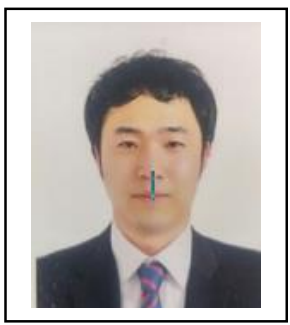

\section{SungHoon Jung}

Oriental Medical Food \& Nutrition Major, Semyung Univ. Graduate School 